\title{
Chemical Profiling Analysis and Identification the Bioactivities of Herbal Compress Extracts
}

\author{
Sumitta Chotikamas ${ }^{1}$, Kraipat Cheenkachorn ${ }^{1}$, Boochita Wongpanit ${ }^{2}$, Prapakorn Tantayotai ${ }^{3}$, and Malinee Sriariyanun ${ }^{2}$ \\ ${ }^{1}$ Department of Chemical Engineering, King Mongkut's University of Technology North Bangkok, Bangkok 10800, Thailand \\ ${ }^{2}$ The Sirindhorn International Thai-German Graduate School of Engineering, King Mongkut's University of Technology North Bangkok, \\ Bangkok 10800, Thailand \\ ${ }^{3}$ Department of Microbiology, Faculty of Science, Srinakarinwirot University, Bangkok 10110, Thailand
}

\begin{abstract}
The traditional Thai herbal compress is composed of six different types of herbs including Ginger (Zingiber cassumunar), Turmeric (Curcuma longa Linn.), Soap Pod (Acacia concinna), Kaffir lime (Citrus hystrix), Lemongrass (Cymbopogon citratus), and Tamarind (Tamarindus indica Linn.). Herbal compress is used in treatment of Thai traditional massage to relieve the body pain and muscle strains. The objective of this work is to perform chemical profiling and extraction modelling of herbal compress obtained from solvent extraction method. The kinetic models, The second order and Fick's second law, representing the extraction behaviors of bioactive compounds were constructed to fit with experimental data of solvent extraction. Under tested condition, the extraction equilibrium was reached after $360 \mathrm{~min}$ and the second-order model gives the best fit for the experimental data with high coefficients of correlation $\left(\mathrm{R}^{2}=0.9927\right)$. Additionally, chemical profiling analysis showed that the amounts and variations of bioactive components in drying-pretreated herbal compress were more abundant than that of untreated sample. This finding could be applied further for preparation and production of traditional Thai herbal compress in the industrial scale.
\end{abstract}

\section{Introduction}

Herbal compress is made of combinations of various types of herbs that are tightly wrapped in a square piece of cloth. Before use, it is steamed in water for 15-20 min to allow the release of active compounds and aromatic oils from herb [1], and then placed directly on the skin to relieve pain and inflammation. Heat in steamed compress stimulates blood circulation and helps to treat sprains and pain. The benefits of using herbal compress in Thai traditional massage are to relax muscle and tendon, to increase body flexibility, to improve range of joint motion, and to enhance circulation of blood [2].

Generally, the main ingredients of Thai herbal compress include Ginger (Zingiber cassumunar), Turmeric (Curcuma longa Linn.), Soap Pod (Acacia concinna), Kaffir lime (Citrus hystrix), Lemongrass (Cymbopogon citratus), Tamarind (Tamarindus indica Linn.). Many researches have been investigated chemical compositions and biological properties of herbs. The main active chemicals of Ginger were identified to be sabinene, $\gamma$-terpinene, terpinen-4-ol and (E)-1-(3,4dimethoxyphenyl) butadiene (DMPBD). DMPBD possesses a potent anti-inflammatory activity [3, 4]. Turmeric contains essential oils that possess various pharmacological activities, for example antioxidant, antimicrobial, anticancer and anti-inflammatory treatments, and the major chemicals, for example ar- turmerone, $\beta$-turmerone, arcurcumene, curlone, cubenol, $\beta$-sesquiphellandrene, germacrone and $\alpha$-zingiberene [57]. Soap Pod helps in getting rid of skin infections and diseases due to its antibacterial properties [8]. Soap pod extracts has been demonstrated to have in vitro antioxidant and anti-tyrosinase activities [9]. Kaffir lime possesses antioxidant, antimicrobial, antibacterial properties and the major compounds are sabinene, $\beta$ pinene, limonene, $\alpha$-pinene, camphene, myrcene, terpinen-4-ol, $\alpha$-terpineol, linalool, terpinolene and citronellal [10-12]. The main compounds in the essential oil of lemongrass are the monoterpene citral, a mixtures of the stereisomers geranial, neral and $\beta$-myrcene and antioxidant properties has also been reported $[13,14]$. Tamarind extract owns antioxidant and anti-inflammatory properties $[15,16]$.

Traditionally, Thai herbal compress could be made of either fresh herb or dried herb. The bioactivities and chemical compositions of the herbs are possibly loss during inappropriate pretreatment process, storage and usage of herbal compress. The database of bioactivities and chemical compositions of Thai herbal compress extracts is currently not yet completely collected. Therefore, the objective of this work is to perform chemical profiling and extraction modelling of herbal compress obtained from solvent extraction method. The extraction models were constructed based on experimental data that could be used to explain the 
phenomena to improve the production and Thai herbal compress in industrial scale.

\section{Materials and methods}

\subsection{Materials}

Ginger (Zingiber cassumunar), Turmeric (Curcuma longa Linn.), Soap Pod (Acacia concinna), Kaffir lime (Citrus hystrix), Lemongrass (Cymbopogon citratus), Tamarind (Tamarindus indica Linn.) were purchased from local market in Bangkok, Thailand. The plant materials were washed with distilled water, chopped into small pieces and dried in hot air oven at $60^{\circ} \mathrm{C}$ for $24 \mathrm{~h}$. Solvents including 95\%ethanol, hexane and water were selected for solid-liquid extraction of plant materials.

\subsection{Solid-liquid extraction}

Twenty grams of plant materials were extracted with 160 $\mathrm{ml}$ of each solvent for $0.5,1,2,3,4,5,6,24$ and $48 \mathrm{~h}$ at $30{ }^{\circ} \mathrm{C}$. The extracts were filtered using filter paper (Whatman No.1).

\subsection{UV-VIS Spectroscopic analysis}

The UV-Visible absorption spectra of the samples were measured on a T80+ PG Instruments Ultraviolet-visible Spectrophotometer (UV-Vis) in the range of 400-700 nm of wavelength.

\subsection{Gas chromatography-mass spectroscopy analysis}

The extracted samples were analyzed by using GC-MS (GCMS-QP2020 Gas Chromatograph Mass Spectrometer, Shimadzu). GC-MS system equipped with a DB-WAX fused capillary column $(30 \mathrm{~m} \times 0.25 \mathrm{~mm}$ and $0.25 \mu \mathrm{m}$ film thickness). Oven temperature was set at $50-250^{\circ} \mathrm{C}$ with ramping rate of $5^{\circ} \mathrm{C} / \mathrm{min}$, carrier gas was helium with a flow rate of $0.69 \mathrm{ml} / \mathrm{min}$ and spilt ratio 1:20.

\subsection{Kinetic models}

Two kinetic models were selected to fit experimental data, Second-order Equation and Fick's law Equation:

\subsubsection{Second-order model}

The second-order kinetic equation $[17,18]$ for the extraction rate can be written as follows:

$$
\frac{d c_{t}}{d t}=k\left(c_{\infty}-c_{t}\right)^{2}
$$

Where $\mathrm{k}$ is the second-order extraction rate constant $\left(\mathrm{Lmol}^{-1} \mathrm{~min}^{-1}\right), \mathrm{C}_{\infty}$ is the concentration of extracted at equilibrium $\left(\mathrm{molL}^{-1}\right), \mathrm{C}_{\mathrm{t}}$ is the concentration of extracted at any time $\left(\mathrm{molL}^{-1}\right)$ and $\mathrm{t}(\mathrm{min})$. Equation (2) is obtained by integrating with the initial and boundary conditions $\mathrm{C}_{t}$ $=0$ at $\mathrm{t}=0$ and $\mathrm{C}_{\mathrm{t}}=\mathrm{C}_{\mathrm{t}}$ at $\mathrm{t}=\mathrm{t}$ and rearranging the following relations:

$$
c_{t}=\frac{c_{\infty}^{2} k t}{1+c_{\infty}^{2} k t}
$$
form:

Equation (2) may be rearranged to obtain the linear

$$
\frac{t}{c_{t}}=\frac{1}{k c_{\infty}^{2}}+\frac{t}{c_{\infty}}
$$

The initial extraction rate, as $\mathrm{C}_{\mathrm{t}} / \mathrm{t}$ when $\mathrm{t}$ approaches 0 , can be defined as:

$$
h=k c_{\infty}^{2}
$$

Equation (3) can be rearranged to finally obtain:

$$
\frac{t}{c_{t}}=\frac{1}{h}+\frac{t}{c_{\infty}}
$$

The initial extraction rate $h$, the concentration of extracted at equilibrium, $\mathrm{C}_{\infty}$ and the second-order extraction rate constant $\mathrm{k}$ can be determined experimentally from the slope and the intercept by plotting $t / C_{t}$ versus $t$. Thus, the concentration of extracted at any time can be described as:

$$
c_{t}=\frac{t}{(1 / h)+\left(t / c_{\infty}\right)}
$$

\subsubsection{Fick's law model}

From Fick's second law [19, 20] derived the applied diffusion model as follows:

$$
\frac{\partial C}{\partial t}=\nabla\left(-D_{e f f} \nabla C\right)
$$

Where $\mathrm{C}$ is the concentration of solute, $\mathrm{t}$ is the time ( $\mathrm{s}$ ) and $D_{\text {eff }}$ is the diffusivity or effective diffusion coefficient of the solute $\left(\mathrm{m}^{2} \mathrm{~s}^{-1}\right)$. The initial and boundary conditions for solving the equation were as follows:

$$
\begin{aligned}
& t=0, C=C_{0} \quad \forall r \\
& t>0, C=C_{i}=0 \quad r=R \\
& t>0, \frac{\partial C}{\partial r}=0 \quad r=0
\end{aligned}
$$

For these the conditions and the assumptions of the mass transfer, Crank [19] proposed the solutions for diffusion in the radial direction (Eq. (8)).

$$
\frac{C-C_{0}}{C_{i}-C_{0}}=1+\left[\frac{2 R}{\pi r} \sum_{n=1}^{\infty} \frac{(-1)^{n}}{n} \sin \frac{\pi n r}{R} \exp \left\{-\frac{D_{\text {eff }} n^{2} \pi^{2} t}{R^{2}}\right\}\right]
$$

The total amount of diffusing substance leaving the sphere as: 


$$
\frac{M}{M_{\infty}}=1-\frac{6}{\pi^{2}} \sum_{n=1}^{\infty} \frac{1}{n^{2}} \exp \left\{-\frac{D_{e f f} n^{2} \pi^{2} t}{R^{2}}\right\}
$$

Where $M_{\infty}$ is the total amount of solute transferred after infinite time, $\mathrm{R}$ is the radius of the sphere $(\mathrm{m})$ and $\mathrm{n}$ is an integer number. The external mass transfer resistance is negligible [20, 21]. Equation (9) can be reduced to the following form:

$$
\frac{M}{M_{\infty}}=\ln \left(\frac{6}{\pi^{2}}\right)-\frac{D_{e f f} \pi^{2} t}{R^{2}}
$$

The concentration of the solute in the extraction solvent at any time following:

$$
\ln \frac{C_{\infty}}{C_{\infty}-C}=0.498+\frac{9.87 D_{e f f} t}{R^{2}}
$$

Where $\mathrm{C}$ is the concentration of the solute in the extraction solvent at time $t, \mathrm{C}_{\infty}$ is the concentration of the solute in the extraction solvent after infinite time.

\section{Results and discussion}

\subsection{Kinetic models}

In this study, plants materials were extracted using the solid-liquid extraction method with three types of solvents as our previous study [22, 23]. Within 360-minperiod observation, the concentration of the extract released from herbal compress was increased rapidly in early period, then later the concentration was gradually increase with slower rate suggesting the equilibrium of extraction. Similar observations were reported by Y.S. Ho. et al. [17] and H.S. Kusuma et al. [24]. This behavior could be explained that during the initial stage of extraction, when the solvent infiltrated into the solid, the high concentration gradient was presented, resulting in the high rates of mass transfer into the liquid phase. As the extraction time gaining, the mass transfer of the solute from solid phase to solvent was limited due to the reducing of concentration gradient.

The simplified mechanism of this behavior involves only two stages, namely washing stage (fast extraction) and diffusion stage (slow extraction) of extracted substances. As a rule, diffusion of extractable substance through plant particles is the rate limiting step of the overall extraction process because external resistance mass transfer is usually negligible $[19,20]$. Therefore, in this study, two kinetic extraction models, Second-order model and Fick's law model were selected to fit with experimental data.

\subsection{Second-order model}

The comparisons between experimental extraction data and second-order rate models of all plant materials were shown in Figure 1. The concentration at equilibrium $\left(\mathrm{C}_{\infty}\right)$, the initial extraction rate $(\mathrm{h})$ and the second-order extraction rate constant $(\mathrm{k})$ were calculated by plotting $\mathrm{t} / \mathrm{Ct}$ versus $\mathrm{t}$ (time) as shown in Table 1.
The result of model fitting to experimental data showed that the Second-order model has average $\mathrm{R}^{2}$ of 0.9927. Previously, R.R. Lovasoa et al. also applied the Second-order model to the Solid-liquid extraction system of Fumaria officinalis and obtained the highest $\mathrm{R}^{2}$ value $[25,26]$.

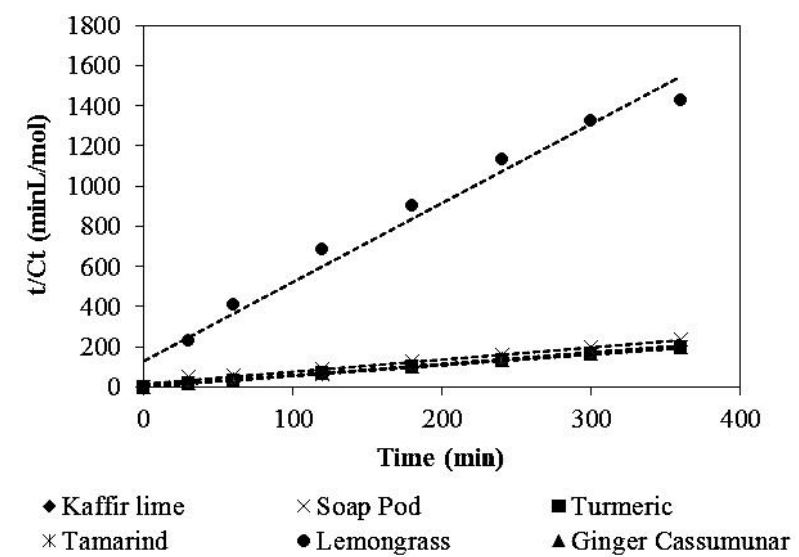

Figure 1. Second-order model represented extraction kinetics of extracts obtained from various plant materials.

Table 1. Linierization of second-order kinetic model of herbal compress extracts.

\begin{tabular}{|c|c|c|c|c|}
\hline Plants & $\begin{array}{c}\mathbf{h} \\
(\mathbf{m o l} / \mathbf{L} \\
\mathbf{m i n})\end{array}$ & $\begin{array}{c}\mathbf{c}_{\infty} \\
(\mathbf{m o l} / \mathbf{L})\end{array}$ & $\begin{array}{c}\mathbf{k} \\
\mathbf{( L / m o l} \\
\mathbf{m i n})\end{array}$ & $\mathbf{R}^{\mathbf{2}}$ \\
\hline Kaffir lime & 1.740 & 0.169 & 0.512 & 0.9998 \\
\hline $\begin{array}{c}\text { Ginger } \\
\text { Cassumunar }\end{array}$ & 0.254 & 0.119 & 0.007 & 0.9750 \\
\hline Soap pod & 1.818 & 0.576 & 1.908 & 1.0000 \\
\hline Turmeric & 1.640 & 0.022 & 0.061 & 0.9820 \\
\hline Tamarind & 1.832 & 0.247 & 0.832 & 0.9999 \\
\hline Lemongrass & 1.827 & 0.356 & 1.191 & 0.9999 \\
\hline \multicolumn{5}{|c}{} \\
\hline
\end{tabular}

\subsection{Fick's law model}

Next, Fick's law model was applied to find the correlation with the experimental data. This model is valid in the case of neglecting external mass transfer resistance. The predicted values were fitted to the experimental data and shown as a series of plots between $\ln \left(\mathrm{C}_{\infty} / \mathrm{C}_{\infty}-\mathrm{C}\right)$ versus $\mathrm{t}$ (time) (Figure 2$)$. The calculation of the diffusivity $\left(\mathrm{D}_{\text {eff }}\right)$ value obtained from the model was shown in Table 2.

It could be found that Fick's law model overlaid well, with average $\mathrm{R}^{2}$ value of 0.9099 , to the experimental data during the early phase of extraction time, especially during $360 \mathrm{~min}$. Compared with the second-order extraction model, the second-order model presented the better correlation to experimental data. This finding could be further studied in more details to draw the proposed behaviors of extraction of herbal compress materials. 


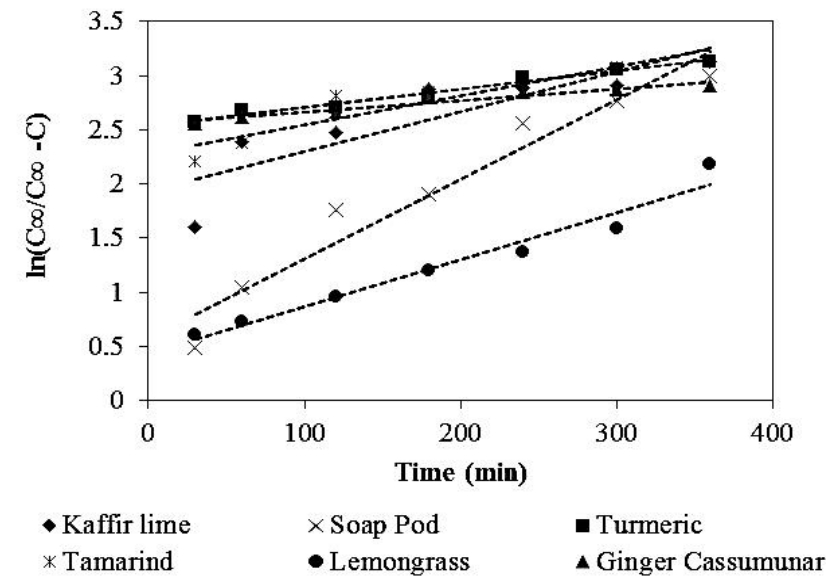

Figure 2. Fick's law model represented extraction kinetics of extracts obtained from various plant materials.

Table 2. Linearization of fick's law kinetic model of herbal compress extracts.

\begin{tabular}{|c|c|c|}
\hline Plants & $\begin{array}{c}\text { Diffusivity } \mathbf{~ 1 0} \\
\left(\mathbf{m}^{\mathbf{2}} \mathbf{\text { s }}\right)\end{array}$ & $\mathbf{R}^{\mathbf{2}}$ \\
\hline Kaffir lime & 3.7 & 0.7641 \\
\hline Ginger Cassumunar & 4.3 & 0.9599 \\
\hline Soap pod & 1.1 & 0.9343 \\
\hline Turmeric & 7.3 & 0.9449 \\
\hline Tamarind & 2.7 & 0.8819 \\
\hline Lemongrass & 1.7 & 0.9748 \\
\hline \multicolumn{2}{|c|}{} \\
\hline
\end{tabular}

\subsection{GC-MS analysis}

The chemical profiles of herbal compress extracts obtained by using three types of solvents were acquired and analyzed with GC-MS as described in our previous studies [22, 23]. The identities of active compounds with their retention time (RT) and \%abundance are shown in Table 3. Comparing chemical profiling obtained from 95\%ethanol, hexane and water, the result showed that there are many chemicals identified in 95\%ethanol and water extracts, but not in hexane extracts. Also, the variations of chemicals in hexane extracts are relatively less compared to $95 \%$ ethanol and water extracts.

In this study, many bioactive chemicals were identified differentially in each types of herbal materials. The main components of extracts from fresh and dried kaffir lime were elemol, $\delta$-cadinene, 3-methyl-3-butenoic acid, acetic acid and $\alpha$-terpineol. $\alpha$-terpineol, which possesses antibacterial, anti-inflammatory properties antifungal activities [27-29], was present with high abundance in ethanol extracts at $10.55 \%$ and $6.92 \%$ of fresh and dry kaffir lime, respectively. The main components of extracts from fresh and dried lemongrass were 2-furanmethanol, acetic acid, 1-hydroxy-2propanone, selina-6-en-4-ol (with 56.3\% abundance and only presents in ethanol extract), and [R,R]-2,3butanediol.
The main components of extracts from fresh and dried ginger were triquinacene,1,4-bis(methoxy) (with 70.27\% abundance), terpinen-4-ol, and -Sesquiphellanderene. The main components of fresh and dried Soap pod extracts were furfural (only presented in water extract with $\quad 7.9 \%$ abundance), linoleic acid, 5hydroxymethylfurfural. This result was confirmed by P. Sombatsiri et al. the compounds of Acacia concinna (Wild.) DC [30]. The main components of extracts from fresh and dried tamarind leaves were sabinene, $\beta$-pinene, $\alpha$-pinene, D-limonene. The main components of extracts from fresh and dried turmeric were turmerone, $\beta$ sesquiphellanderene, terpinen-4-ol, $\beta$-bisabolene. It has been reported that the major compositions found in turmeric oil are $\alpha$-phellanderen, terpinolen, $\alpha$-zingiberene, r-turmerone, $\beta$-sequiphellanderen and $\alpha$-turmerone [31].

The results indicated that ethanol and water were the most suitable solvents for extraction of herb from herbal compress. Interestingly, the traditional method to prepare herbal compress before use with consumer is done by using water steam. This study brought about the concern how to improve the effectiveness of compress for medicinal purpose. That is, to maximize the release of bioactive compounds from herbal compress, the mixed ethanol and water could be suggested.

Addtionally, the pretreatment method by drying of herbal materials has an effect on the profiles of remaining bioactive components, in both variation and abundance. Extracts with pretreatment with drying oven slightly gained abundance of major components compared to without pretreatment. This observation is similar to previous study that the essential oil of dried $C$. citratus leaves gave the highest amount of essential oil on dry weight basis [32].

\section{Conclusion}

In this study, the extracts of herbal compress were prepared by using solid-liquid extraction method and analyzed for chemical compositions. The influence of solvent type and pretreatment method were studied and the result showed that the pretreatment and solvent type have effects on the profiles of bioactive components of the herbal compress extracts. The kinetics of the solvent extraction were studied and correlated with two different extraction models. The results demonstrated that the second-order model achieved the best fit for the experimental data.

\section{Acknowledgment}

The authors would like to thank National Science and Technology Development Agency (NSTDA with STEM program), Srinakarinwirot University (Research grant No. 540/2560) and TF Cosmetology Co. LTD. for the financial support of this research. 
Table 3. The major chemical components of herbal compress extracts.

\begin{tabular}{|c|c|c|c|c|c|c|c|c|c|}
\hline & \multirow{3}{*}{ No } & \multirow{3}{*}{ RT } & \multirow{3}{*}{ Compound } & \multicolumn{6}{|c|}{ \% Abundance } \\
\hline & & & & \multicolumn{2}{|c|}{ 95\% Ethanol } & \multicolumn{2}{|c|}{ Hexane } & \multicolumn{2}{|c|}{ Water } \\
\hline & & & & Fresh & Dry & Fresh & Dry & Fresh & Dry \\
\hline \multirow{10}{*}{ 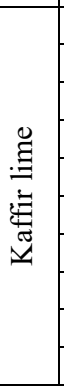 } & 1 & 12.331 & 1-Hydroxy-2-propanone & - & - & - & - & 6.03 & 8.65 \\
\hline & 2 & 17.735 & Acetic acid & 3.92 & - & - & - & 24.21 & 26.07 \\
\hline & 3 & 18.043 & 2-Propanone, 1-(acetyloxy) & & - & - & - & 2.29 & 3.28 \\
\hline & 4 & 22.064 & $\alpha$-Terpineol & 10.55 & 6.92 & - & - & - & - \\
\hline & 5 & 23.011 & $\delta$-Cadinene & - & 21.26 & 2.36 & - & - & - \\
\hline & 6 & 23.752 & 3-Methyl-3-butenoic acid & 13.46 & - & - & - & 20.11 & 22.72 \\
\hline & 7 & 23.520 & 3-Methyl-2-butenoic acid & 6.82 & - & - & - & - & 5.61 \\
\hline & 8 & 28.063 & Elemol & - & 13.6 & 48.62 & 30.88 & - & - \\
\hline & 9 & 29.255 & (1R,7S,E)-7-Isopropyl-4,10-dimethylenecyclodec-5-enol & - & 4.92 & 4.16 & - & - & - \\
\hline & 10 & 29.854 & $\alpha$-Cadinol & - & - & 5.19 & - & - & - \\
\hline \multirow{10}{*}{ 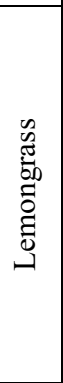 } & 1 & 3.050 & Formic acid & 92.07 & - & - & - & - & - \\
\hline & 2 & 12.368 & 1-Hydroxy-2-propanone & - & - & - & - & 7.56 & 13.16 \\
\hline & 3 & 16.116 & Sulfurous acid, 2-ethylhexyl hexyl ester & - & - & 4.95 & 13.8 & - & - \\
\hline & 4 & 17.716 & Acetic acid & - & - & - & - & 27.93 & 20.25 \\
\hline & 5 & 21.190 & Hexacosane,1-iodo- & - & - & 5.98 & 6.13 & - & - \\
\hline & 6 & 21.447 & 2-Furanmethanol & 0.79 & - & - & - & 3.84 & 1.31 \\
\hline & 7 & 25.107 & {$[\mathrm{R}, \mathrm{R}]-2,3$-butanediol } & - & - & - & & - & 53.96 \\
\hline & 8 & 28.120 & dl-Glyceraldehyde dimer & 1.96 & - & - & - & 18.52 & - \\
\hline & 9 & 29.372 & Benzene, (1-propyloctyl)- & - & - & - & 16.01 & - & - \\
\hline & 10 & 29.557 & Selina-6-en-4-ol & - & 56.3 & - & - & - & - \\
\hline \multirow{10}{*}{ 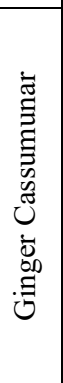 } & 1 & 3.021 & Formic acid & 22.88 & - & - & - & - & - \\
\hline & 2 & 12.396 & 1-Hydroxy-2-propanone & - & - & - & - & 10.15 & - \\
\hline & 3 & 17.720 & Acetic acid & - & - & 2.27 & - & 27.86 & 30.13 \\
\hline & 4 & 20.267 & {$[\mathrm{R}, \mathrm{R}]-2,3$-butanediol } & - & - & - & - & - & 62.58 \\
\hline & 5 & 20.644 & Terpinen-4-ol & 27.33 & 3.1 & - & - & - & - \\
\hline & 6 & 23.185 & $\beta$-Sesquiphellanderene & 9.53 & 2.61 & 21.55 & - & - & - \\
\hline & 7 & 26.872 & Triquinacene, 1,4-bis(methoxy) & - & 70.27 & - & & - & - \\
\hline & 8 & 28.122 & dl-Glyceraldehyde dimer & 2.24 & - & - & - & 18.43 & - \\
\hline & 9 & 29.503 & 2,2-dimethyl-4,5-di-1-propenyl-1,3-Dioxolane & 2.87 & - & - & - & - & 0.35 \\
\hline & 10 & 29.868 & 2-Methoxy-4-vinylphenol & 12.3 & 2.28 & - & - & - & 0.92 \\
\hline \multirow{10}{*}{ 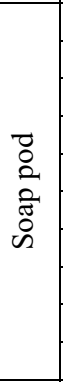 } & 1 & 11.941 & Furfural & - & - & - & - & - & 7.9 \\
\hline & 2 & 16.382 & $2(5 \mathrm{H})$-Furanone & - & 5.95 & - & - & - & 9.42 \\
\hline & 3 & 21.369 & 1-Methyl-pyrrolidine-2-carboxylic acid & - & - & - & - & - & 9.72 \\
\hline & 4 & 22.818 & 5-Hydroxypipecolic acid & - & 15.32 & - & - & - & - \\
\hline & 5 & 24.228 & Hexadecanoic acid, ethyl ester & - & 16.57 & - & - & - & - \\
\hline & 6 & 25.294 & Propanoic acid & - & - & - & - & - & 9.85 \\
\hline & 7 & 27.557 & Octadecanoic acid, ethyl ester & - & 7.68 & - & - & - & - \\
\hline & 8 & 28.103 & 5-Hydroxymethylfurfural & - & 5.57 & - & - & - & 13.29 \\
\hline & 9 & 28.647 & Linoleic acid & - & 5.41 & - & - & - & - \\
\hline & 10 & 29.695 & Ethyl linolenate & - & 8.69 & - & - & - & - \\
\hline \multirow{10}{*}{ 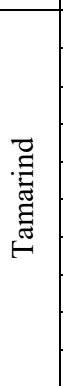 } & 1 & 4.448 & $\alpha$-Pinene & - & - & - & 3.54 & - & - \\
\hline & 2 & 6.175 & $\beta$-Pinene & - & 7.23 & - & 35.41 & - & - \\
\hline & 3 & 6.320 & Sabinene & - & 5.61 & - & 22.75 & - & - \\
\hline & 4 & 8.538 & D-Limonene & - & 6.19 & - & 19.15 & - & - \\
\hline & 5 & 17.890 & 3-Furaldehyde & - & - & - & - & - & 26.49 \\
\hline & 6 & 20.075 & 5-Methylfurfural & - & 0.83 & - & - & - & 6.89 \\
\hline & 7 & 23.107 & 1,2-Cyclopentanedione & - & - & - & - & - & 4.21 \\
\hline & 8 & 27.122 & 1H-Pyrrole-2-carboxaldehyde & - & - & - & - & - & 4.32 \\
\hline & 9 & 28.597 & 4,5-Dimethyl-1,3-dioxol-2-one & - & - & - & - & - & 13.51 \\
\hline & 10 & 29.437 & 5-Hydroxypipecolic acid & - & 6.31 & - & - & - & - \\
\hline & 1 & 12.380 & 1-Hydroxy-2-propanone & - & - & - & - & 11.91 & 14.84 \\
\hline & 2 & 17.761 & Acetic acid & - & - & - & - & 53.89 & 57.13 \\
\hline & 3 & 23.186 & $\beta$-Sesquiphellanderene & 7.76 & - & 0.78 & - & - & - \\
\hline & 4 & 24.862 & 1,4(15),11-Eudesmatriene & 1.06 & 9.18 & - & 1.45 & - & \\
\hline 可 & 5 & 25.500 & Terpinen-4-ol & - & 8.55 & - & - & - & - \\
\hline 春 & 6 & 27.311 & 7-epi-sesquithujene & - & 16.31 & - & 26.23 & - & - \\
\hline & 7 & 27.374 & Beta.-Bisabolene & & & - & 5.17 & - & - \\
\hline & 8 & 28.043 & $\beta$-Sesquiphellanderene & - & & - & 49.21 & - & - \\
\hline & 9 & 29.403 & Phenol, 2-methoxy- & & 34.02 & - & 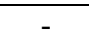 & - & - \\
\hline & 10 & 29.741 & Turmerone & 76.92 & & 83.71 & - & - & 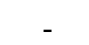 \\
\hline
\end{tabular}




\section{References}

1. The Institute of Thai Traditional Medicine, The Public Manual of Health Care with Thai Traditional Medicine, The War Veterans Organization of Thailand Under Royal Patronage of His Majesty the King Publishing, Bangkok, Thailand, (2009)

2. W. Kumnerddee, Journal of the Medical Association of Thailand, 92, 117 (2009)

3. U. Sukatta, P. Rugthaworn, P. Punjee, S. Chidchenchey, V. Keeratinijakal, Kasetsart Journal Natural Science, 43, 212 (2009)

4. R. Jeenapongsa, K. Yoovathaworn, K. M. Sriwatanakul, U. Pongprayoon, K. Sriwatanakul, J. Ethnopharmac, 87, 143 (2003)

5. H. P. T. Ammon, M. A. Wahi, Planta Med, 57, 1 (1991)

6. D.-W. Kim, S.-M. Lee, H.-S. Woo, J.-Y. Park, B.-S. Ko, J.-D. Heo, Y.-B. Ryu, W.-S. Lee, Journal of Functional Foods, 26, 485 (2016)

7. L. Zhang, Z. Yang, F. Chen, P. Su, D. Chen, W. Pan, et al., Industrial Crops and Products, 109, 60 (2017)

8. M. Wuthi-udomlert, O. Vallisuta, Pharmacogn J., 3, 69 (2011)

9. W. Poomanee, W. Chaiyana, N. Intasai, P. leelapornpisid, Int J Pharm Pharm Sci, 7, 237 (2015)

10. S. Siripongvutikorn, P. Thummaratwasik, Y. Huang, LWT-Food Science and Technology, 38, 347 (2005)

11. V. Srisukh, C. Tribuddharat, V. Nukoolkarn, N. Bunyapraphatsara, K. Chokephaibulkit, S. Phoomniyom, et al., ScienceAsia, 38, 212 (2012)

12. N. Kasuan, Z. Muhammad1, Z. Yusoff1, M. H. F. Rahiman, M.N. Taib, Z. A. Haiyee, MJAS, 17, 359 (2013)

13. M R Santin, A O Santos, C. Nakamura \& B. P. D. Filho ,I. C. P. Ferreira, T. Ueda-Nakamura, Parasitol Res, 105, 1489 (2009)

14. M. d. C. Vázquez-Briones, L. R. Hernández, J. A. Guerrero-Beltrán, J F R, 4, 36 (2015)
15. SS. Bhadoriya, V. Mishra, S. Raut, A. Ganeshpurkar, SK. Jain, Sci Pharm, 80, 685 (2012)

16. P. Kuru, APJTB, 4, 676 (2014)

17. Y.-S. Ho, H.-O.H. Adamou, H. Fauduet, C. Porte, Separation and Purification Technology, 45, 169 (2005)

18. H.-O.H. Adamou, H. Fauduet, C. Porte, Y.-S. Ho, Chemical Engineering Communications, 194, 537 (2007)

19. J. Crank, The Mathematics of Diffusion, 2nd edition. Oxford, UK., (1975)

20. C.-H. Chan, R. Yusoff, G.-C. Ngoh, ChERD, 92, 1169 (2014)

21. M. Pinelo, J. Sineiro, M. J. Nunez, Journal of Food Engineering, 77, 57 (2006)

22. S. Chaichoowong, J.B. Bol, P. Bol, T. Gamse, M. Sriariyanun, Oriental Journal of Chemistry, 33, 66 (2017)

23. C. Muenmuang, M. Narasingha, T. Phusantisampan, M. Sriariyanun, ACM International Conference Proceeding Series Part F130950, 119 (2017)

24. H.S. Kusuma, M. Mahfud, International Food Research Journal, 24, 1697 (2017)

25. R-R. Lovasoa, J-L. Havet, C. Porte, H. Fauduet, Separation and Purification Technology, 54, 253 (2007)

26. R-R. Lovasoa, J-L. Havet, C. Porte, H. Fauduet, Industrial Crops and Products, 29, 516 (2009)

27. S. Held, P. Schieberle, V. Somoza, J.Agric. Food Chem, 55, 8040 (2007)

28. R. Kotan, S. Kordali, A. Cakir, ZNC, 62, 507 (2007)

29. D. Pitarokili, M. Couladis, P-P. Niki, O. Tzakou, J.Agric. Food Chem, 50, 6688 (2002)

30. P. Sombatsiri, G. Chairote, In Proc. WOCMAP III,: Quality, Efficacy, Safety, Processing \& Trade in MAPs., 189 (2005)

31. G. Asghari, A. Mostajeran, M. Shebli, RPS, 4, 55 (2009)

32. A.R. Mohamed Hanaa, Y.I. Sallam, A.S. El-Leithy, Safaa E. Aly, AOAS, 57, 113 (2012) 